\title{
PUBLIC REACTION TO COVID-19 ON TWITTER: A THEMATIC ANALYSIS
}

\author{
Akif Mustafa ${ }^{1}$ \\ ${ }^{1}$ Research Fellow, \\ International Institute for Population Sciences, \\ Mumbai, India
}

\author{
Subham Kumar Mohanta ${ }^{3}$ \\ ${ }^{3}$ Research Fellow, \\ International Institute for Population Sciences, \\ Mumbai, India
}

\author{
Imaduddin Ansari ${ }^{2}$ \\ ${ }^{2}$ Research Fellow, \\ International Institute for Population Sciences, \\ Mumbai, India
}

\author{
Shalem Balla ${ }^{4}$ \\ ${ }^{4}$ Research Fellow, \\ International Institute for Population Sciences, \\ Mumbai, India
}

Article DOI: $\underline{\text { https://doi.org/10.36713/epra4518 }}$

\begin{abstract}
Emergency situations typically lead to a plethora of public attention on social media platforms like 'Twitter'. Twitter provides a unique opportunity for public health researchers to analyze untampered information shared during a disease outbreak. Considering the ongoing public health emergency, we conducted a study investigating the public reaction to COVID-19 pandemic around the world using in-depth thematic analysis of Twitter data. A dataset of 212846 tweets was retrieved over a period of seven days (from April 13, 2020, to April 19, 2020) via Twitter Application Programme Interface (API). The following five keywords were used to collect the tweets: “coronavirus", “covid-19”, "corona”, “covid", "covid19”. After data filtering and cleaning 6348 tweets were randomly selected for in-depth thematic analysis. Thematic analysis was done manually using a two-level coding guide. A total of six main themes emerged from the analysis: 'sentiments and feelings', 'Information', 'General Discussion', 'Politics', 'Food', and 'Sarcasm or humor'. The aforementioned themes were divided into 26 sub-themes. The results of the thematic analysis show that $30.1 \%$ of the tweets were regarding 'sentiments and feelings', $15.6 \%$ were regarding 'politics', and $6.5 \%$ were related to 'sarcasm or humor'. The present study is the first study that has analyzed the public response to COVID-19 on Twitter. The study demonstrates that social media platforms (like Twitter) can be used to conduct infodemiological studies related to public health emergencies like the COVID-19 pandemic. We believe that the results of this study will be of potential interest to policymakers, health authorities, stakeholders, and public health and social science researchers.
\end{abstract}

KEYWORDS:COVID-19, Twitter, Social Media, Coronavirus, Lockdown, Pandemic

\section{INTRODUCTION}

The world is passing through a serious public health emergency with the emergence and spread of severe acute respiratory syndrome coronavirus 2 (SARS-CoV-2, COVID-19). In December 2019, the government of Wuhan, China stated that there are cases of serious illness causing severe pneumonia, after few days the researchers identified a new virus that infected many people in the region, and on $7^{\text {th }}$ January 2020 the virus was identified as coronavirus ("A Timeline of the Coronavirus Pandemic - The New York Times," n.d.). On $11^{\text {th }}$ January 2020 the state media of Wuhan, China reported the first death caused by the new virus. After that the number of cases soared exponentially, 
spreading in other parts of China and outside China (Singhal, 2098). On 30 ${ }^{\text {th }}$ January 2020 World Health Organization (WHO) declared a global emergency, and on $11^{\text {th }}$ March 2020 WHO characterized COVID -19 as pandemic ("W.H.O. Declares Global Emergency as Wuhan Coronavirus Spreads - The New York Times," n.d.),("Coronavirus (COVID-19) events as they happen," n.d.). As of April 24, 2020, more than 2.7 million cases have been reported worldwide with over 1.9 lakh deaths caused by COVID-19 (Worldometer, 2020).

Apart from mortality and morbidity, pandemics like COVID-19 have the potential of causing significant social, economic, and political disruption (Nita Madhav, 2017). From the past outbreaks, we learned that pandemics can cause acute economic damage, including short-term fiscal shocks and longerterm damage to economic growth (Achonu, Laporte, \& Gardam, 2005). Countries with frail establishments and inheritances of political flimsiness, pandemics can lead to political stresses and tensions creating clashes between states and citizens, damaging state capacity, driving population migration, and heightening social tension and discrimination (Morse, 2009),(McCoy, 2014). Increased risk of mortality/morbidity, economic damage, lockdown, quarantine, political tension, etc. are common during a pandemic and these factors can cause individual behavioral and emotional changes like anger, frustration, stress, grief, boredom, etc. (Nita Madhav, 2017)

These kinds of events are likely to lead public opinions, views, and expression of emotions towards the disease and the events that are taking place during the pandemic. It was later part of the $20^{\text {th }}$ century when people started sharing their feeling, emotions, and opinions on online platforms. Previous lethal outbreaks occurred in the $20^{\text {th }}$ century, such as that of an influenza flu pandemic (1918-1920), occurred in the absence of communication devices like personal computers and mobile phones. The 2009 swine flu pandemic, the 2014 Ebola epidemic, and the 2016 Zika virus outbreak occurred in the age of internet-based social media platforms such as Twitter and Facebook. This makes it possible to analyze and examine public views, opinions, feeling, and emotions shared during these outbreaks using the data of these social media platforms.

Twitter is a free microblogging platform formed in 2006 ("Twitter - Wikipedia," n.d.) which a006Clows users to share 280 or less than 280-character text messages, known as 'tweets', through these tweets people share their feelings, emotions opinions and views in front of the world (Chew \& Eysenbach, 2010).
The service has around 330 million registered users and approximately 500 million tweets are sent every day ("• Twitter by the Numbers (2020): Stats, Demographics \& Fun Facts," n.d.). These tweets contain a wealth of information, analysis of these tweet data can provide an instantaneous snapshot of the public's opinions, emotions, and behavioral responses. So Twitter provides a unique opportunity for public health researchers to analyze untampered information shared during a pandemic. In the past, a number of studies related to infectious diseases outbreaks and pandemics have been conducted using Twitter data (Ahmed \& Bath, n.d.),(Chew \& Eysenbach, 2010),(Signorini, Segre, \& Polgreen, 2011),(Ahmed, Bath, Sbaffi, \& Demartini, 2018),(Kostkova, Szomszor, \& St. Luis, 2014),(Mcclellan, Ali, Mutter, Kroutil, \& Landwehr, 2017).

The goal of our exploratory study is to provide deep insight into the types of information shared on Twitter amidst the COVID-19 outbreak. More specifically the objectives of the study were:

- To analyze the Twitter data regarding COVID-19 obtained through Twitter's streaming application programmer's interface (API)

- To develop a well-defined two-level coding framework.

- To manually label the tweets according to the framework in order to get an idea about different types of information shared by the people during the COVID-19 pandemic.

The results of the study will be of potential interest to policymakers, health authorities, stakeholders, and public health and social science researchers.

\section{METHODS}

\section{Design}

Case study approach has been utilized for the present study. This approach has been used in many past research studies conducted on Twitter data (Chew \& Eysenbach, 2010),(Bosley et al., 2013),(Scanfeld, Scanfeld, \& Elaine Larson, n.d.),(Robillard, Johnson, Hennessey, Beattie, \& Illes, 2013),(Kostkova et al., 2014),(Signorini et al., 2011). In this study thematic analysis was utilized to analyze the tweets. Thematic analysis is a method of analyzing qualitative data, it is used to identify, analyze, and interpret the patterns and interior hidden themes of a qualitative data (Guest, MacQueen, \& Namey, 2012). We used a bottom-up approach involving the formation of two levels: Main themes and Sub-Themes. 


\section{Data collection and data filtering}

Using the Twitter Application Programme Interface (API), a total of $n=212846$ original tweets in English were collected over a period of 1 week from April 13, 2020, to April 19, 2020 (reply's and retweets were not included in the dataset). For extraction of tweets we used the following five keywords: (a) covid19, (b) coronavirus, (c) COVID, (d) corona, (e) COVID-19. No restrictions on location or gender or age were placed for data collection. Table-1 is showing the number of tweets collected per day.

A previous study found that if popular content are not removed from the dataset then it can lead to the potential bias of dominance of popular content in the analysis (Bruns \& Liang, 2012). Tweets of popular persons are retweeted many times with exact content or minor modification, so there are high chances that the same tweet gets included two times or more than two times in the dataset. To eliminate this problem, duplicate and near-duplicate tweets were removed at a $70 \%$ threshold leading to a total of 126960 unique tweets. As the dataset was quite large $(n=126960)$, an analysis of the whole dataset might not have been a feasible option, so a subset of the dataset was chosen using random sampling for in-depth qualitative analysis.

Table 1. No. of tweets collected per day

\begin{tabular}{cc}
\hline Day & No. of Tweets \\
\hline 13-Apr-20 & 30133 \\
14-Apr-20 & 30084 \\
15-Apr-20 & 31023 \\
16-Apr-20 & 30210 \\
17-Apr-20 & 30007 \\
18-Apr-20 & 29845 \\
19-Apr-20 & 31544 \\
\hline
\end{tabular}

\section{Coding}

The tweets were randomized and $5 \%$ of the tweets $(n=6348)$ were selected for in-depth thematic analysis.

To construct a robust coding guide, 400 tweets distributed among the four researchers (100 tweets each) for pilot analysis. All the four researchers were instructed to label the allocated tweets among the possible themes/sub-themes as per their knowledge. After that, all the suggested themes/sub-themes were collected and each theme/sub-theme was discussed rigorously. A coding guide of themes/subthemes was finalized through consensus among the researchers. To test intercoder reliability, 250 tweets were randomly selected and given to researchers to categorize according to coding guide, i.e. each tweet was coded by the four researchers independently. We manually calculated Fliess Kappa to check intercoder reliability. Fliess Kappa is a statistical tool used to measure intercoder reliability when there are more than two coders (Fleiss, 1971). Intercoder reliability percentage was found to be $92.8 \%$ and kappa (к) was found to be 0.82 .

The tweets $(n=6348)$ were then divided among the four researchers for in-depth manual thematic analysis.

\section{RESULTS}

\section{Overview of themes}

In this section, we would discuss the various themes and sub-themes that we have discovered in our study, and has been presented in Table-2. We discovered 6 main themes among which the tweets were labeled. These themes are:

- Theme 1: Sentiments and Feelings

- Theme 2: Information

- Theme 3: General discussion/ comment

- Theme 4: Political

- Theme 5: Food

- Theme 6: Sarcasm or Humor

We also had an additional theme named as "Irrelevant" and numbered as Theme 99. 
Table 2. Overview of themes and sub-themes

\begin{tabular}{|c|c|c|c|}
\hline $\begin{array}{l}\text { Sr. } \\
\text { No. }\end{array}$ & Theme (N/\%) & Subthemes & n (\%) \\
\hline \multirow[t]{10}{*}{1} & \multirow[t]{10}{*}{$\begin{array}{l}\text { Sentiments } \\
(1911 / 30.1 \%)\end{array}$} & 1.1 General fear/Worry/upset/concerned & $\begin{array}{c}244 \\
(3.8 \%)\end{array}$ \\
\hline & & 1.2 Anger & $\begin{array}{c}109 \\
(1.7 \%)\end{array}$ \\
\hline & & 1.3 Hate speech & $\begin{array}{c}41 \\
(0.6 \%)\end{array}$ \\
\hline & & 1.4 Hope/positive tweet/joy & $\begin{array}{c}195 \\
(3.1 \%)\end{array}$ \\
\hline & & 1.5 Opinion/suggestion & $\begin{array}{c}397 \\
(6.3 \%)\end{array}$ \\
\hline & & $\begin{array}{l}\text { 1.6 Frustration/missing something/bored/sad (due to } \\
\text { lockdown) }\end{array}$ & $\begin{array}{c}358 \\
(5.6 \%)\end{array}$ \\
\hline & & 1.7 Appreciation/praising/thanks & $\begin{array}{c}191 \\
(3.0 \%)\end{array}$ \\
\hline & & 1.8 Grief/Mourn & $\begin{array}{c}120 \\
(1.9 \%)\end{array}$ \\
\hline & & 1.9 Critisizing (someone/organization) & $\begin{array}{c}207 \\
(3.3 \%)\end{array}$ \\
\hline & & 1.10 Praying & $\begin{array}{c}49 \\
(0.8 \%)\end{array}$ \\
\hline \multirow[t]{7}{*}{2} & \multirow[t]{7}{*}{ Information (1460/23.0\%) } & 2.1 General information related to corona/news & $\begin{array}{c}576 \\
(9.1 \%)\end{array}$ \\
\hline & & 2.2 Incidence/Prevalence/testing/recovered & $\begin{array}{c}556 \\
(8.8 \%)\end{array}$ \\
\hline & & $\begin{array}{l}2.3 \text { Prevention techniques/tools/products/Testing } \\
\text { technique }\end{array}$ & $\begin{array}{c}129 \\
(2.0 \%)\end{array}$ \\
\hline & & 2.4 Signs and Symptoms & $\begin{array}{c}30 \\
(0.5 \%)\end{array}$ \\
\hline & & 2.5 Diagnosis & $\begin{array}{c}19 \\
(0.3 \%)\end{array}$ \\
\hline & & 2.6 References to other infection or disease & $\begin{array}{c}23 \\
(0.4 \%)\end{array}$ \\
\hline & & 2.7 Seeking/providing/requesting for help & $\begin{array}{c}127 \\
(2.0 \%)\end{array}$ \\
\hline \multirow[t]{4}{*}{3} & \multirow[t]{4}{*}{$\begin{array}{ll}\text { General } & \text { discussion/comment } \\
(1415 / 22.3 \%) & \end{array}$} & 3.1 General discussion & $\begin{array}{c}709 \\
(11.2 \%)\end{array}$ \\
\hline & & 3.2 Information seeking/question & $\begin{array}{c}173 \\
(2.7 \%)\end{array}$ \\
\hline & & 3.3 Economic discussion/unemployment & $\begin{array}{c}204 \\
(3.2 \%)\end{array}$ \\
\hline & & 3.4 Voice of Sanity & $\begin{array}{c}329 \\
(5.2 \%)\end{array}$ \\
\hline \multirow[t]{3}{*}{4} & \multirow[t]{3}{*}{ Political } & 4.1 General political discussion & $\begin{array}{c}326 \\
(5.1 \%)\end{array}$ \\
\hline & & 4.2 Trump & $\begin{array}{c}310 \\
(4.9 \%)\end{array}$ \\
\hline & & 4.3 Critisizing govt/stakeholders/political party & $\begin{array}{c}270 \\
(4.3 \%)\end{array}$ \\
\hline
\end{tabular}




\begin{tabular}{lllc} 
& & 4.4 Praising govt/stakeholders/political party & $(1.3 \%)$ \\
\hline $\mathbf{5}$ & Food $(11 / 0.2 \%)$ & 5.1 Bat Consumption & 11 \\
\hline $\mathbf{6}$ & Sarcasm or Humour (413/6.5\%) & \multirow{2}{*}{ 6.1 Sarcastic } & $(0.2 \%)$ \\
& & \multirow{2}{*}{6.2 Humour } & 148 \\
& & & $2.3 \%)$ \\
& & $(4.2 \%)$ \\
\hline $\mathbf{9 9}$ & Irrevelant $(147 / 2.3 \%)$ & & \\
\hline
\end{tabular}

\section{Theme 1: Sentiments and Feelings}

Here we had considered the tweets which expressed various sentiments and feelings about the outbreak of coronavirus.

During the current time of the outbreak, Twitter users might be receiving various information from different sources, leading to cause anxiety and fear on Twitter and among the general public. There are chances that the users in the tweets above might be attempting to perpetuate fear rather than being genuinely afraid. However, given the immediacy of Twitter, and the exaggerated vocabulary it was observed that it is possible that the users were experiencing a high level of fear, but were tweeting in such a way that their fear and the actual risk were exaggerated beyond normal proportions. Some of these tweets are:

"I feel very sad to hear that a Hillsborough survivor succumbed to Covid-19 today."

"Oh charming! I have to have a Covid-19 test tomorrow for my persistent coughing. Doubt I have \#coronavirus but this is the most wicked bronchitis I have ever encountered."

"My great uncle has Covid. He was in a nursing home. He's on a ventilator. He cried when they took him, because he's scared."

There were tweets that expressed the feelings of anger or rage among the people, this is because they have been affected their schedules due to the outbreak of coronavirus. For example:

"I hate coronavirus so fu*kin much."

There were some tweets that were expressing hatred towards a specific person, a religious community, or a nation. For example:

"Because of few why 1.3 billion people life is kept on stake either shoot at site or deploy army in single source areas \#coronavirus"

"these Chinese bastards should be hanged till death"

There were tweets where people expressed hope with positive and joyous tweets to keep the hope in the minds of the people alive that soon things would return back to normal. "keep calm guys!!!! we will get through corona shit soon"

$6.3 \%$ of the tweets were having a content in which tweeters expressed their opinion or proposed a suggestion. e.g.:

"Coronavirus is the second biggest threat to healthcare workers in India. Human beings continue to be the first".

"A phased plan to slowly reopen the country is useless without mass testing for Coronavirus! I'm not understanding why that's a hard concept to our leaders."

Now, due to the sudden declaration of lockdown by the government, there were various problems faced by the people initially, but with the continuation of the lockdown slowly they started getting frustrated, missing things, bored, and sad. Some examples of tweets referring to such sentiments and feelings are:

"Perks of turning 21 during corona..... none, absolutely fu*king none."

"Meant to be playing in a cup final tonight!! Nice one! \#COVID19 Covid Sucks Pass It On!”

"corona broke my heart more than any boy ever will"

There were tweets shared by the users to appreciate, praise, or thank some person, institution, or organization. For instance, one user tweeted:

"The doctors, nurses \& all health workers have selflessly devoted their time and effort in keeping us safe as we battle COVID-19. This \#WorldHealthDay is an ode to their compassion and love for their work. A Big Thank You! $\square$ ",

There were some tweets in which users expressed their grief for those who are suffering from the virus or died: "RIP to those who died in 2020 due to COVID-19. Dont skip this without leaving a heart."

There was another subtheme which included those tweets which expressed prayers:

"May Allah Pak cure the world from Covid-19 before Ramadan...Ameen"

\section{Theme 2: Information}

Tweets which discussed general information and news related to Corona, Incidence, Prevalence, Testing, Recovery, prevention and testing techniques, 
discussion about Signs, Symptoms, and diagnosis, comparing or referencing Covid-19 with other infection and disease and also seeking, providing and requesting for help were branched among this category. The majority of the Tweeters have discussed the transmission of Covid-19 in very general terms, while others were sharing information or reporting on the number of diagnosed cases or according to the location of a reported case.

"Mexico reported 450 new \#COVID19 cases, bringing the total number of cases to 6297. It also added 37 new deaths, increasing the total number of deaths to 486."

There were a number of users who were making some sane tweets and they were concerned about safety and prevention, like:

"Coronavirus. Prevent infection regularly wash your hands for 20 seconds and don't touch your face, eyes, nose and mouth."

Tweets about the method and awareness of diagnosing the disease were also encountered, there were a number of Tweeters which were tweeting a lot, how to be sure that you have Covid-19 and Tweets about various medication were also found, some of them are as follows:

"Covid-19 testing available. No appointment necessary."

" $\square$ These can be breathed in, or can cause an infection if you touch a surface they have landed on, and then touch your face with unwashed hands."

Discussion about other Pandemics was also found, most of them were comparing and giving references this pandemic with past epidemics and especially those which were related to respiratory disease. There were people who were comparing Covid-19 with influenza and the common cold. For example, one user tweeted:

"These symptoms are similar to the flu (influenza) or the common cold, which are a lot more common than COVID-19.@TeamForPakistan”

People were also discussing about giving and seeking help in this hour of need (pandemic) like the tweet stated below:

"Betway just donated 150,000 cedis to the Covid-19 fund

Finally I can say, I've also donated to that fund"

\section{Theme 3: General Discussion/Comments}

There were a huge number of tweets that were making very general comments related to COVID-19. Out of those Tweets, some were generally asking questions and some were either discussing economic or other frightening scenarios and also, there were people who were making sane statements.

"I don't know but I hear the flu death numbers are dropping dramatically. It is funny how that is happening at the same time COVID-19 death numbers are going up dramatically."

There were a lot of tweets related to economic discussion and frightening scenarios which speaks of both economic and frightening scenarios which could take place due to this pandemic.

"The economic impact of this corona $p$ is deeper than y'all think"

“@DavidGHFrost Let's kill the economy for good ... Covid19 means 35\% cut in GDP on Q2... add brexit it will means a good $50 \%$ cut on GDP with no trade deal ... Enjoy the worst recession ever !"

A number of Tweeters were doing a great job by just making sane statements. These tweets were discussing precautionary guidelines, advice of social distancing, etc.:

"COVID19 We need to work together to slow the spread!"

"please stay at home. You're not only risking your life but also the lives of those around you. COVID-19 doesn't care who you are."

\section{Theme 4: Politics}

Tweets which included political discussions either passing rhetorical statement or praising or criticizing the government or giving any statement which had any taste of politics were included in this category. In general, there were discussions related to general politics, governments, and countries in one or the other way. For example:

"\#COVID19: According to reports, \#US Intelligence officials warned \#Israel about the \#Coronavirus outbreak in \#China back in November. As we now know, the \#Chinese govt only informed the world about the virus on December 31st. Makes one wonder if this could have been prevented?"

There were tweets related to Trump which included all the tweets made by the Twitter users with a reference to Trump, in their tweets some were praising Trump, some were trolling and some were criticizing him, majority of the tweets found about Trump were having negative sentiments, For example:

"Donald J. Trump is the leading cause of death in the United States. 34,522 \#coronavirus deaths in the U.S. as of this \#FridayMorning. \#Trump knew. He did nothing. He is still doing nothing.

There was another subtheme of tweets in which users were criticizing government, a political party, stakeholders, or an organization. e.g.

"This virus is showing how much in denial the government is in about COVID-19. There's no way they're taking this seriously...these rules have so many 
loopholes."

"The government must be taken to Court for allowing politicization Covid-19 aid."

Just opposite to the previous subtheme, there was another sub-theme including the tweets used to praise any government or political party or some of the doings of an organization or stakeholder. For example:

"Thank you_Saudi_Arabia for showing the world such an amazing example of Humanity and Kindness during this \#Covid_19 crisis"

\section{Theme 5: Food}

There were only a few tweets that were discussing about food, actually all the tweets in this category mentioned bat in it, maybe because scientists believe that COVID-19 originated in bats. For e.g.:

"She: I was wondering how bat tastes like?

Me: Corona"

\section{Theme 6: Sarcasm or Humor}

This theme includes those tweets which are referred to general sarcasm and humor which mentioned Covid-19 and included subthemes of sarcasm and humor related to popular culture, nervous humor, and understanding as well as that of sarcasm and general humor including trolling. E.g.

"if everyone simply stops breathing corona won't spread"

"Idk what's growing faster, death by covid 19 or females making only fans"

There were lots of people who were making fun of other things also.

"One condom I mean just one condom would have prevented the birth of the person who created corona virus"

"covid-19 is definitely a woman"

There were many tweets that were having a sarcastic tone. Sarcasm is an ironic or satirical remark tempered by humor. For example:

"You can't get kids to wear bicycle helmets good luck with getting them to wear mask"

"Tweeps $i$ sincerely need your help,,,I need $20 \mathrm{k}$ urgently, I promise to pay back immediately after @MBuhari pays us our COVID-19 money"

\section{Theme 7: Irrelevant}

Those Tweets which are vague and has almost no relation with Covid-19 or Corona disease, we put those type of tweets under the theme of Irrelevant because it has nothing to do with this Pandemic. Plus, what most of the Tweeters in this category did was, they just used the hashtag of COVID-19 and corona for wider reach and visibility, frankly speaking, there were some tweets having very shady and hazy content and we were not able to put them in any other sub-theme. Examples of such are given below:
"LUCCI just dropped some music called Corona pack"

“•StayTuned@SuriyaFansClub.B $\square$

Fans Club Activities Update

\#Coronavirus | \#SFCWelfareWorks"

Above mentioned tweets show their nature, by just skimming upon it one can say that these tweets are irrelevant and should not be associated with the hashtag of Covid-19 or Corona.

\section{DISCUSSION}

The point of the current research was to study the content of tweets using in-depth thematic analysis and to analyze sorts of discussions that were taking place in the midst of COVID -19. Globally, a lot of research studies related to COVID -19 have been done and many are in progress, however, as per the best of our knowledge till now there is no study conducted which has examined the public response to the COVID19 epidemic on social media. Though there has been a study conducted in China analyzing the reaction of Chinese people to COVID -19 on a blogging site (Zhao \& Xu, 2020), but the study was only focused on the Chinese population and didn't use big global social media platforms like Twitter.

Whenever a disease outbreak occurs in a region, it affects the population of that area not only in terms of physical health but also mental health ("An 'Epidemic Within an Outbreak:' The Mental Health Consequences of Infectious Disease Epidemics | O'Neill Institute," n.d.),(Pfefferbaum \& North, 2020),29. It has been found in previous studies that a pandemic or an epidemic can instigate fear, anger, frustration, tension, anxiety, etc. Talking about the severity of the COVID19 pandemic, WHO has characterized it as 10 times deadlier than the 2009 swine flu pandemic ("WHO says Covid-19 is 10 times more deadly than swine flu," n.d.). The virus has compelled a major proportion of the world population to live under a state of complete lockdown ("3.9 billion people are currently called on to stay in their homes due to coronavirus | Daily Mail Online," n.d.). In these kinds of situations, extreme emotions (anger, tension, depression, anxiety, stress, etc.) and psychological disturbance are obvious in the population (Pfefferbaum \&North, 2020),("Psychiatrists Beware! The Impact of COVID-19 and Pandemics on Mental Health | Psychiatric Times," n.d.). In our study, we also found traces of the aforementioned sentiments and feelings among Twitter users. While doing thematic analysis we found that people were worried about what would happen in their future, some expressed fear by mentioning increasing numbers of COVID-19 cases and deaths, while some were skeptical regarding their future career. There were 
many tweeters who were frustrated due to lockdown and they were in favor of lifting the lockdown, as a result we saw many anti-lockdown protests across the countries ("Coronavirus lockdown: Americans protest the 'Stay-at-home' order - Lifting the lockdown | The Economic Times,” n.d.),(“Anti-lockdown protest in London sees man arrested after group hug outside police HQ | The Independent," n.d.),("Coronavirus: Group hugs are the new weapon of anti-lockdown protesters - Business Insider," n.d.),("Small turnout at Ottawa anti-lockdown protest | CTV News," n.d.). Even in such a situation, there were people who have kept the light of hope alive in their minds. They are continuously putting forward their efforts in the form of opinions and suggestions with positive and joyful tweets to keep the hope in the minds of people alive so that they keep on with the thought that the scenario would very soon be normal and everyone would return back to their full-fledged normal life.

Regarding information about Covid-19, there were valuable pieces of information which were shared like the general information about Covid-19 which includes prevalence monitoring, recoveries, and deaths due to Covid-19, information about the preventive measures, symptoms, and diagnosis of Covid-19 were also shared which was the need of the hour, it seems important to share such valuable information on Twitter because in these moments misinformation and fear-mongering information are also shared by a large number of people which contains some hidden agendas. Plus, people also shared information about the other similar diseases which were having similar causalities like influenza and $\mathrm{H} 1 \mathrm{~N} 1$ virus and there were also some good people which were offering help to the needy by providing them Masks, Sanitizers, and also providing Food and Fodders. Additionally, there were many people who were using Twitter to seek help or to motivate people to donate to the needy population.

Apart from other consequences, another grieve consequence of COVID-19 is economic damage all over the world. The industries have stopped working, millions of the people lost their job and transportation has become minimal leading to economic slump ("Covid-19: US unemployment claims hit roughly 26 mn, highest since Depression," n.d.),("COVID-19: impact could cause equivalent of 195 million job losses, says ILO chief | UN News," n.d.),(“Coronavirus Impact on Global Economy: Global economy could shrink by almost $1 \%$ in 2020 due to COVID-19 pandemic: United Nations - The Economic Times," n.d.). In these kinds of situations, the concern of the public is obvious and that's what we saw in our study, even in these conditions of public health emergency and unfavorable conditions people were concerned about the economy. Many people were even in favor of lifting of lockdown and opening up the industrial work, putting their and the lives of others at risk.

Twitter is a very powerful platform to reach out to the masses, and some people are wisely utilizing its this feature by raising the voice of reason. there were people who were really making some sensible talk, such as people who were talking about, cleanliness, the use of masks, and requesting the peoples to follow the rules of social distancing.

Regarding the political discussions occurring in the current scenario of the COVID-19 outbreak, there were tweets generally discussing about political parties, leaders, political actions and political events occurring in the respected countries. President Donald Trump was quite frequently mentioned in the discussion among Twitter users. A lot many tweets had in reference to Trump, mostly criticizing and blaming him for not making wise decisions on time and putting the country at high risk. On the other hand, there were many users who were praising their leaders and government for various reason, for example, India's prime minister Modi was praised by many users.

In our analysis we also found a number of tweets having a humorous or sarcastic tone, actually, users were not making fun of the COVID-19 pandemic but they were using the reference of the pandemic in a context that would be humorous. These kinds of tweets have a positive impact on readers. Previous research studies have found that humor has the potential to benefit psychologically (Dunn, 1993),(Åstedt-Kurki, Isola, Tammentie, \& Kervinen, 2001),(DEAN \& GREGORY, 2004). One study established that "Humor has the potential of maintaining a collegial relationship, managing stressful situations, and maintaining a sense of perspective" (Dean \& Gregory, 2004).

\section{CONCLUSION}

The study demonstrates that social media platforms (like Twitter) can be used to conduct infodemiological studies related to public health emergencies like the COVID-19 pandemic. The present study comprehensively explains the infodemiology of COVID-19 on Twitter. Public health researchers and stakeholders should consider the utility of social media platforms like Twitter in policy framing and implementations.

\section{LIMITATIONS}

The present study has some limitations that can be addressed in future studies. First, the study was based on only one social media platform - Twitter. 
There are a number of social media platforms like Facebook, Instagram, etc. where people discuss and express their opinions and feelings, in further studies researchers can include the data of these platforms for a more robust analysis. Secondly, the study was limited to a period of 7-days, which may result in less validity.

The tweets we extracted were based on 5 keywords: "coronavirus", "covid-19", "corona", "covid", "covid19". There is a possibility that people could have tweeted information and opinions about covid-19 without using any of these hashtags. Plus, there is one more possibility that they may have used another hashtag, maybe in their native language.

There is one more possibility that tweets about COVID -19 have been tweeted in other languages apart from English that we have excluded.

\section{Funding}

The author(s) received no financial support for the research, authorship, and/or publication of this article.

\section{Conflict of Interest}

The authors declare no conflicts of interest regarding the publication of this paper.

\section{REFERENCES}

1. - Twitter by the Numbers (2020): Stats, Demographics \& Fun Facts. (n.d.). Retrieved April 25, 2020, from https://www.omnicoreagency.com/twitter-statistics/

2. 3.9 billion people are currently called on to stay in their homes due to coronavirus | Daily Mail Online. (n.d.). Retrieved May 2, 2020, from https://www.dailymail.co.uk/news/article8181001/3-9-billion-people-currently-called-stayhomes-coronavirus.htm

3. A Timeline of the Coronavirus Pandemic - The New York Times. (n.d.). Retrieved April 24, 2020, from https://www.nytimes.com/article/coronavirustimeline.html

4. Achonu, C., Laporte, A., \& Gardam, M. A. (2005). The financial impact of controlling a respiratory virus outbreak in a teaching hospital: Lessons learned from SARS. Canadian Journal of Public Health, 96(1), 52-54. https://doi.org/10.1007/BF03404018

5. Ahmed, W., \& Bath, P. (n.d.). The Ebola epidemic on Twitter: challenges for health informatics. https://doi.org/10.1371/journal.pone.0019467

6. Ahmed, W., Bath, P. A., Sbaffi, L., \& Demartini, G. (2018). Moral panic through the lens of Twitter: An analysis of infectious disease outbreaks. In ACM International Conference Proceeding Series (pp. 217-221). Association for Computing Machinery. https://doi.org/10.1145/3217804.3217915

7. An "Epidemic Within an Outbreak:" The Mental Health Consequences of Infectious Disease
Epidemics $\mid$ O'Neill Institute. (n.d.). Retrieved May 2, 2020, from https://oneill.law.georgetown.edu/epidemic-withinoutbreak-mental-health-consequences-infectiousdisease-epidemics/

8. Anti-lockdown protest in London sees man arrested after group hug outside police $H Q \mid$ The Independent. (n.d.). Retrieved May 4, 2020, from https://www.independent.co.uk/news/uk/crime/coro navirus-arrest-anti-lockdown-protests-group-huglondon-met-police-headquarters-a9496446.html

9. Åstedt-Kurki, P., Isola, A., Tammentie, T., \& Kervinen, U. (2001). Importance of humour to client-nurse relationships and clients' well-being. International Journal of Nursing Practice, 7(2), 119-125. https://doi.org/10.1046/j.1440172X.2001.00287.x

10. Bosley, J. C., Zhao, N. W., Hill, S., Shofer, F. S., Asch, D. A., Becker, L. B., \& Merchant, R. M. (2013). Decoding twitter: Surveillance and trends for cardiac arrest and resuscitation communication. Resuscitation, 84(2), 206-212. https://doi.org/10.1016/j.resuscitation.2012.10.017

11. Bruns, A., \& Liang, Y. E. (2012). Tools and methods for capturing Twitter data during natural disasters. First Monday, 17(4). https://doi.org/10.5210/fm.v17i4.3937

12. Chew, C., \& Eysenbach, G. (2010). Pandemics in the age of Twitter: Content analysis of tweets during the 2009 H1N1 outbreak. PLoS ONE, 5(11), e14118.

https://doi.org/10.1371/journal.pone.0014118

13. Coronavirus: Group hugs are the new weapon of anti-lockdown protesters - Business Insider. (n.d.). Retrieved May 4, 2020, from https://www.businessinsider.com/coronavirusgroup-hugs-are-new-weapon-of-anti-lockdownprotesters-2020-5?IR=T

14. Coronavirus (COVID-19) events as they happen. (n.d.). Retrieved April 24, 2020, from https://www.who.int/emergencies/diseases/novelcoronavirus-2019/events-as-they-happen

15. Coronavirus Impact on Global Economy: Global economy could shrink by almost $1 \%$ in 2020 due to COVID-19 pandemic: United Nations - The Economic Times. (n.d.). Retrieved May 2, 2020, from

https://economictimes.indiatimes.com/news/internat ional/business/global-economy-could-shrink-byalmost-1-in-2020-due-to-covid-19-pandemicunited-nations/articleshow/74943235.cms

16. Coronavirus lockdown: Americans protest the "Stay-at-home" order - Lifting the lockdown | The Economic Times. (n.d.). Retrieved May 4, 2020, from

https://economictimes.indiatimes.com/news/internat ional/world-news/coronavirus-lockdownamericans-protest-the-stay-at-home-order/liftingthe-lockdown/slideshow/75290023.cms 
17. COVID-19: impact could cause equivalent of 195 million job losses, says ILO chief $\mid$ UN News. (n.d.). Retrieved May 2, 2020, from https://news.un.org/en/story/2020/04/1061322

18. Covid-19: US unemployment claims hit roughly 26 mn, highest since Depression. (n.d.). Retrieved May 2, 2020, from https://www.livemint.com/news/world/covid-19-usunemployment-claims-hit-roughly-26-mn-highestsince-depression-11587668709851.html

19. DEAN, R. A. K., \& GREGORY, D. M. (2004). Humor and laughter in palliative care: An ethnographic investigation. Palliative and Supportive Care, 2(2), 139-148. https://doi.org/10.1017/s1478951504040192

20. Dunn, B. (1993). Use of therapeutic humour by psychiatric nurses. British Journal of Nursing (Mark Allen Publishing), 2(9), 468-473. https://doi.org/10.12968/bjon.1993.2.9.468

21. Fleiss, J. L. (1971). Measuring nominal scale agreement among many raters. Psychological Bulletin, 76(5), 378-382. https://doi.org/10.1037/h0031619

22. Guest, G., MacQueen, K., \& Namey, E. (2012). Introduction to applied thematic analysis GOOD FOR INTERP AND FURTHER READING. Applied Thematic Analysis, 3-20. https://doi.org/http://dx.doi.org/10.4135/978148338 4436

23. Kostkova, P., Szomszor, M., \& St. Luis, C. (2014). Swineflu: The use of twitter as an early warning and risk communication tool in the 2009 Swine Flu Pandemic. ACM Transactions on Management Information Systems, 5(2), 1-25. https://doi.org/10.1145/2597892

24. Mcclellan, C., Ali, M. M., Mutter, R., Kroutil, L., \& Landwehr, J. (2017). Using social media to monitor mental health discussions-evidence from Twitter. Journal of the American Medical Informatics Association, 24(3), 496-502. https://doi.org/10.1093/jamia/ocw133

25. McCoy, T. (2014, September 16). Why the brutal murder of several Ebola workers may hint at more violence to come - The Washington Post. The Washington Post. Retrieved from https://www.washingtonpost.com/news/morningmix/wp/2014/09/19/why-the-brutal-murder-ofeight-ebola-workers-may-hint-at-more-violence-tocomel

26. Morse, S. A. (2009). Contagion and Chaos: Disease, Ecology, and National Security in the Era of Globalization. Emerging Infectious Diseases, 15(11), $\quad 1881 \mathrm{~b} \quad$ - $\quad 1882$ https://doi.org/10.3201/eid1511.090577

27. Nita Madhav, B. O. M. G. P. M. E. R. and N.W. (2017). Chapter 17 Pandemics: Risks, Impacts, and Mitigation. In G. H. H. S. et al. Jamison DT (Ed.), Disease Control Priorities: Improving Health and Reducing Poverty (3rd ed.). Washington: The
International Bank for Reconstruction and Development / The World Bank. Retrieved from https://www.ncbi.nlm.nih.gov/books/NBK525302/

28. Pfefferbaum, B., \& North, C. S. (2020). Mental Health and the Covid-19 Pandemic. New England Journal of Medicine. https://doi.org/10.1056/nejmp2008017

29. Psychiatrists Beware! The Impact of COVID-19 and Pandemics on Mental Health | Psychiatric Times. (n.d.). Retrieved May 2, 2020, from https://www.psychiatrictimes.com/psychiatristsbeware-impact-coronavirus-pandemics-mentalhealth

30. Robillard, J. M., Johnson, T. W., Hennessey, C., Beattie, B. L., \& Illes, J. (2013). Aging 2.0: Health Information about Dementia on Twitter. PLoS ONE, $\quad$ 8(7), 69861. https://doi.org/10.1371/journal.pone.0069861

31. Scanfeld, D., Scanfeld, V., \& Elaine Larson, M. L. (n.d.). Dissemination of health information through social networks: Twitter and antibiotics. https://doi.org/10.1016/j.ajic.2009.11.004

32. Signorini, A., Segre, A. M., \& Polgreen, P. M. (2011). The use of Twitter to track levels of disease activity and public concern in the U.S. during the influenza A H1N1 pandemic. PLoS ONE, 6(5). https://doi.org/10.1371/journal.pone.0019467

33. Singhal, T. (2098). A Review of Coronavirus Disease-2019 (COVID-19) https://doi.org/10.1007/s12098-020-03263-6

34. Small turnout at Ottawa anti-lockdown protest | CTV News. (n.d.). Retrieved May 4, 2020, from https://ottawa.ctvnews.ca/small-turnout-at-ottawaanti-lockdown-protest-1.4922218

35. Twitter - Wikipedia. (n.d.). Retrieved April 24, 2020, from https://en.wikipedia.org/wiki/Twitter

36. W.H.O. Declares Global Emergency as Wuhan Coronavirus Spreads - The New York Times. (n.d.). Retrieved April 24, 2020, from https://www.nytimes.com/2020/01/30/health/corona virus-world-health-organization.html

37. WHO says Covid-19 is 10 times more deadly than swine flu. (n.d.). Retrieved May 2, 2020, from https://www.france24.com/en/20200413-who-sayscovid-19-is-10-times-more-deadly-than-swine-flu

38. Worldometer. (2020). Coronavirus Cases. https://doi.org/10.1101/2020.01.23.20018549V2

39. Zhao, Y., \& Xu, H. (2020). Chinese Public Attention to COVID-19 Epidemic: Based on Social Media. MedRxiv, 2020.03.18.20038026. https://doi.org/10.1101/2020.03.18.20038026 